\title{
The role of information presentation formats in belief updating
}

\author{
Yung-Cheng Shen \\ Yuan-ze University, Taoyuan, Taiwan
}

\author{
Chih-Wei Hue
}

National Taiwan University, Taipei, Taiwan

\begin{abstract}
$T$ he effects of the format by which information is presented on the cognitive processes of belief updating were investigated in the present research. Because of the differences in the affordance of verbal vs. numerical information, it is predicted that the belief updating processes involved in processing verbal and numerical information would be different. Specifically, the additive rule is used to combine information using verbal formats, while the averaging rule is used to combine information using numerical formats. Two experiments were conducted to test these hypotheses. Experiment 1 tested the belief updating process in the positive direction, and Experiment 2 tested the process in the negative direction. Two independent variables were manipulated: information presentation format (verbal vs numerical) and presentation order (strong-weak vs weak-strong). The participants were asked to adjust their purchase likelihood of a consumer product based on the sequential presentations of two experts' opinions. These two opinions varied in their formats (verbal vs. numerical) and strengths (strong vs weak). The two opinions were presented in either the strong-weak order or the weak-strong order. Participants were instructed to first anchor their purchase likelihood at $50 \%$, and then adjust the purchase likelihood, first based on the first expert's opinion, and second based on both experts' opinions. In both experiments the hypotheses that participants employed an additive rule to integrate verbal information and an averaging rule to integrate numerical information were supported.
\end{abstract}

es effets du format dans lequel l'information est présentée sur les processus cognitifs actifs lors de la mise à
jour des croyances ont été étudiés dans la présente recherche. Compte tenu des différences dans la
présentation de l'information verbale versus numérique, il était attendu que les processus de mise à jour des
croyances impliqués dans le traitement de l'information verbale ou numérique seraient différents. Plus
précisément, il était attendu que la règle additive serait utilisée pour combiner les informations présentées sous un
format verbal, tandis que la règle de la moyenne serait utilisée pour combiner les informations présentées sous un
format numérique. Deux expérimentations ont été menées afin de tester ces hypothèses. La première a testé le
processus de mise à jour des croyances dans la direction positive; la deuxième a testé le processus dans la direction
négative. Deux variables indépendantes ont été manipulées : le format de présentation de l'information (verbal ou
numérique) et l'ordre de présentation (fort-faible ou faible-fort). Lors de l'expérimentation, on a demandé aux
participants d'ajuster leur probabilité d'achat d'un produit de consommation en se basant sur les présentations
séquentielles d'opinions de deux experts. Ces deux opinions variaient dans leur format (verbal ou numérique) et
leur force (fort ou faible). Les deux opinions étaient présentées soit dans l'ordre fort-faible ou l'ordre faible-fort.
Les participants devaient d'abord ancrer leur probabilité d'achat à $50 \%$, puis ajuster leur probabilité d'achat une
première fois en se basant sur l'opinion du premier expert et, une seconde fois, en se basant sur l'opinion des deux
experts. Dans les deux expérimentations, les hypothèses selon lesquelles les participants emploient la règle
additive pour combiner les informations verbales et la règle de la moyenne pour combiner les informations
numériques ont été confirmées.

$\boldsymbol{C}^{1}$ presente estudio analiza el efecto del formato de presentación de la información en el procesamiento cognitivo de actualización de las creencias. Al tener en cuenta las diferencias entre la presentación verbal vs. Numérica de la información se esperaba que el proceso de actualización de las creencias en caso de la información

Correspondence should be addressed to Yung-Cheng Shen, Department of Business Administration, Yuan-ze University, 135 Yuan-Tung Rd, Neili, Taoyuan, 320, Taiwan. (E-mail: ycs@saturn.yzu.edu.tw).

This research was supported by the National Science Council grant project (Project number: 89-2413-H-155-001-). The authors wish to thank Arthur B. Markman and two anonymous reviewers for their valuable comments on the paper, as well as two research assistants, Jui-Ping Huang and Ya-Ting Ko, for their assistance in data collection. 
numérica y verbal fuera distinto. En concreto, la regla de adición es la que se utiliza para combinar la información en formato verbal, mientras que para combinar la información numérica se utiliza la regla de promedio. Para comprobar estas hipótesis se realizó dos experimentos. En el Experimento 1 se verificó la hipótesis sobre la actualización de las creencias en la dirección positiva y en el Experimento 2 en la dirección negativa. Se manipuló dos variables independientes: el formato de presentación de la información (verbal vs numérico) y el orden de la presentación (fuerte-débil vs débil-fuerte). Se pidió a los participantes que indicaran la probabilidad de adquisición de un producto basándose en la secuencia de las opiniones de dos expertos. Estas opiniones variaban en cuanto al formato (verbal vs. Numérico) y fuerza (fuerte vs débil). Las dos opiniones fueron presentadas en dos diferentes órdenes: fuerte-débil o bien débil-fuerte. Al principio se instruyó a los participantes para fijar la probabilidad de adquirir el producto en el $50 \%$ e ir ajustando la probabilidad por primera vez basándose en la opinión del primer experto y la segunda vez en las opiniones de ambos expertos. En los dos experimentos se comprobó la hipótesis en la que se afirma que los participantes emplean la regla de adición para integrar la información verbal y la regla de promedio para la integración de la información numérica.

Imagine that Joan is planning to buy a notebook computer. She believes IBM is a big brand name that one can trust so she picks up a current issue of $P C$ Magazine, scans the ads for information suitable to her needs, and finds that the functions and price of the IBM notebook computer, model $\mathrm{X}$, fit her needs well. Joan has a positive attitude toward IBM model $\mathrm{X}$ based on the results of her research and therefore plans to buy it. The next day, however, she visits a website containing user evaluations of the computers people have bought. One user offered some negative comments concerning this specific type of IBM notebook computer; the comments lead Joan to adjust her evaluation of the model $\mathrm{X}$ downward, or negatively. Two days later, she calls a friend, David, who is a computer expert, for help. David tells her that the negative comments she saw on the web referred to the previous version of the IBM model $X$. The new IBM model $\mathrm{X}$ works nicely and does not have the problems the user mentioned. As a result, Joan reaffirms her confidence in the product, and finally purchases it.

Scenarios like the one described above happen every day. To make decisions or to solve problems, a person needs to process sequentially presented information, and to integrate the different pieces of information based on their input order. That is, while the person is updating her/his beliefs or attitudes toward the product under consideration, she/he is experiencing an "anchoring-and-adjustment" process (Tversky \& Kahneman, 1974). In this process, not only the valence of the information, but also the information type and the presentation order may affect the direction and magnitude of the attitude adjustment. For instance, the same information can be presented in either a verbal format or a numerical format, and these formats may also influence the process. It is a central goal of the current research to study how different information presentation formats may influence the information integration processes.

Belief updating has been researched extensively in psychology (e.g., Anderson, 1981; Benassi, 1982; Curley, Young, Kingry, \& Yates, 1988; Furnham, 1986; Hogarth \& Einhorn, 1992; Lichtenstein \& Srull, 1987; Luchins \& Luchins, 1986; Tetlock, 1983; Tversky \& Kahneman, 1974; Yates \& Curley, 1986). These studies have identified an assortment of factors affecting the process of integrating information, but relatively little research has been conducted concerning the effects of the information presentation formats on belief updating. The purpose of the present research is to address how the information integration process is influenced by information presentation formats. The following sections first discuss the conceptual background of the research and then describe the results of two empirical studies.

\section{CONCEPTUAL BACKGROUND}

\section{Models of belief updating}

As described in the above example, belief updating is a daily cognitive activity in which people engage. One important phenomenon that has received intensive research attention in the processes of belief updating is the order effect (Nisbett \& Ross, 1980). Order effects have been defined and explored in different ways. Some have looked at how the specific serial position of information can influence people's overall judgments (e.g., Pennington \& Hastie, 1986). In these studies the primacy effect and the recency effect are the focus of the interest. Others, in contrast, investigated how the same information presented in different 
orders can result in different judgments (e.g., Hogarth \& Einhorn, 1992). In these studies, participants were required to integrate multiple pieces of information presented in various orders, and cognitive processes as a function of different information orders were investigated. The order effect in these studies is often discussed in the broader context of information integration: Namely, the cognitive processes people employ to integrate information in general.

One of the most influential theoretical frameworks in the research of information integration is Anderson's Information Integration Theory (1981, 1991). According to this theory, people employ cognitive algebra to integrate multiple pieces of information. Cognitive algebra is the arithmeticlike (such as addition and multiplication) cognitive operations people employ to integrate information. In this regard, order effects result from the use of different mechanisms of cognitive algebra in the process of information integration. For instance, Graesser and Anderson (1974) showed that the perceived "size" of a gift was the multiplicative combination of the sender's income and the value of the gift. Levin, Johnson, and Faraone (1984) showed that people use the multiplying rule to trade off between the price and the quality of commercial products. Aside from multiplication, Anderson has proposed a number of cognitive algebraic rules, such as an averaging rule, to account for how people make judgments.

Hogarth and Einhorn (1992) went further to identify conditions under which a specific rule would be used. They distinguished between evaluation tasks and estimation tasks. In an evaluation task, information is encoded as either positive or negative relative to the hypothesis being evaluated. Supportive evidence for a hypothesis increases one's belief strength in that hypothesis, while disconfirming evidence decreases it (Carlson \& Dulany, 1988; Einhorn \& Hogarth, 1986). In such an "additive" process, information can be viewed as bipolar, scaled between -1 and +1 , relative to the hypothesis (see Hogarth \& Einhorn, 1992; Lopes, 1982, 1985, 1987). Positive information increases its strength and negative information decreases it.

In an estimation task, an averaging rule is at work in which a "moving average" is computed to reflect the psychological strength for each new piece of information relative to the current hypothesis (Shanteau, 1975). In Hogarth and Einhorn's model, the information to be integrated in an estimation task is seen as unipolar, scaled between 0 and 1 (see also Lopes, 1982, 1985, 1987).
New information is averaged with all previous information to form a new "anchor" of attitude.

Much research on information integration implicitly assumed that a certain rule, such as "averaging" (e.g., Johar, Jedidi, \& Jacoby, 1997; West \& Broniarczyk, 1998), would be used in a given situation. However, in these studies it did not seem that there was a strong argument to justify why any specific rule should be adopted. As indicated by Anderson (1981), there is an assortment of information integration rules (e.g., additive, multiplicative, or averaging rules) that could potentially be employed. There is no a priori reason to believe why any specific rule should be used; however if certain contextual factors exist they may determine the adoption of certain information integration rules. Thus it is important to discern these contextual factors that determine which specific rule would be used in a given situation. The present research postulates that one such factor is the format (e.g., a verbal vs. numerical information format) with which information is presented. The research therefore investigated how different information integration rules may be adopted as a function of the format of the input information.

\section{Effects of information format on judgments}

The attributes of a product can be represented in a variety of ways. The two most common ways to express one's evaluation of an attribute are verbal and numerical formats. A statement such as "This car has very good horsepower" is an example of one's evaluation of the attribute "horsepower" in a car; the "value" of this attribute is expressed using a verbal format (i.e., "very good"). In contrast, the statement "The horsepower of this car outperforms $80 \%$ of the cars in its class" is an example of using a numerical format (i.e., $80 \%$ ) to describe an attribute value. Although psychological equivalence can be established between verbal and numerical formats (Hue, Peng, Shen, \& Yang, 1990; Lindberg, Garling, \& Montgomery, 1988; Wallsten \& Barton, 1982), the results of decisionmaking research indicate that different cognitive processes will be elicited by verbal or numerical information, which, in turn, will lead a respondent to make different judgments (e.g., Childers \& Viswanathan, 2000; Viswanathan \& Childers, 1996). For example, Stone and Schkade (1991, 1994) found that, compared to numerical formats, verbal formats lead to more alternative-based processing and less compensatory processing. Lindberg, Garling, and Montgomery (1991), on 
the other hand, found that people's choices and preferences can be better predicted when attributes are described with numerical rather than verbal formats. Furthermore, Sen (1998) reported an interaction effect of category knowledge and types of scales on the attraction effect (cf. Huber, Payne, \& Puto, 1982). In particular, experts who have more knowledge in the domain of choice are less susceptible to the attraction effect than novices when information is presented in numerical forms. Finally, outside the context of judgment and decision making, the information format (i.e., type of scale) was found to influence other aspects of human behaviour as well, such as reaction time (Viswanathan \& Narayanan, 1992, 1994), persuasiveness (Yalch \& Yalch, 1984), and the capacity to comprehend and remember TV commercials (Scammon, 1977).

In sum, rich evidence exists documenting the effects of the format with which information is presented on human behaviour. The present study focused on researching whether the information presentation formats (i.e., verbal vs. numerical formats) would affect belief updating processes. It is suggested that verbal versus numerical formats can induce different cognitive algebras in integrating information. The next section presents the detailed rationale of the experimental predictions.

\section{Difference of verbal versus numerical formats in adopting information integration rules}

In the present study, we investigated the conditions under which a certain information integration rule would be employed. As indicated by the results of Stone and Schkade (1991, 1994), information expressed in different formats is likely to be processed differently using different algebraic rules, which in turn leads to different judgments. In particular, the present research postulates that verbal formats should trigger a person to use the additive rule to integrate the information, while numerical formats should lead a person to use the averaging rule. The prediction was made based on the following reasons: Numbers can be manipulated arithmetically (e.g., adding, subtracting and averaging), while verbal formats cannot; thus, numerical and verbal information is likely to bear different "affordance." The notion of "affordance" was first introduced by Gibson (1977) to describe the actionable properties of an object perceived by an actor (a person or an animal). In other words, affordance corresponds to the relationship between an actor and the object upon which the actor is acting. Information presented in numerical vs verbal formats bear different affordance. Numerals possess the properties of interval, if not ratio scales, and thus allow an actor with arithmetic knowledge to manipulate them arithmetically. In contrast, the verbal description of a person's evaluation of an object is more like a semi-ordinal scale. Although in specific cultures certain consistencies exist among people about how a verbal format should be used, individual or idiosyncratic usage still exists. Thus, given the semi-ordinal property of verbal formats, these do not afford arithmetical operations, but they do allow a person to modify her/his attitude according to the meanings the verbal formats convey. Moreover, Payne, Bettman, and Johnson (1993) argued that while making decisions, processing strategies are constructed online, rather than being retrieved from a predetermined invariant checklist. In an online situation where processing time and cognitive resources are limited, a verbal format that is inherently ambiguous does not permit sophisticated operations such as averaging. Therefore a rough adjustment operation of one's attitude, such as an additive rule, is more "affordable." In contrast, a numerical format that allows precise arithmetic operations is more affordable for an averaging operation.

To test the above predictions, the participants of the present research were asked to express their purchase intentions of some commercial products in the form of purchase likelihoods. In an experimental trial, a product under evaluation was briefly described, and two experts' evaluations of the product, which might be in either verbal or numerical formats, were presented sequentially. These evaluations vary in their valences (positive vs negative) and strengths (strong vs weak). Thus, a participant would be expected to go through an anchoring-and-adjustment process to form her/his attitude toward the product. Assuming that $\mathrm{S}$ is a strong piece of information, and $\mathrm{W}$ is a weak one, when $\mathrm{S}$ and $\mathrm{W}$ are presented in different orders (i.e., S-W vs W-S), an order effect on a participant's attitude change may or may not happen, depending on the format of the experts' evaluation scales. When verbal formats are used, it is expected that the participant would employ an additive rule to integrate the information. For instance, the degree of attitude adjustment upon receiving an S$\mathrm{W}$ sequence of information could be represented using the symbols "s + w," where s represents "large" adjustments , and w represents "small" adjustments. In contrast, the adjustment upon receiving a W-S sequence would be " $w+$ s." Because $(\mathrm{s}+\mathrm{w})$ is equal to $(\mathrm{w}+\mathrm{s})$, the final attitude adjustment should be the same irrespective of the 
order in which the two pieces of information were presented. Therefore, no order effect is predicted for the use of verbal formats.

In contrast, using a numerical format, which is assumed to lead to an averaging operation, would result in an order effect. In a W-S sequence, the first adjustment is "w," and the result of the second adjustment should be the averaging of $\mathrm{W}$ and $\mathrm{S}$, that is, $(\mathrm{w}+\mathrm{s}) / 2$. Because $(\mathrm{w}+\mathrm{s}) / 2$ is greater than $w$, the second adjustment should move one's evaluation of a product upward from the first to the second adjustment. On the other hand, in the $\mathrm{S}-\mathrm{W}$ sequence, the first adjustment is "s," while the second adjustment should be $(s+w) / 2$. Since $(s+$ w) $/ 2$ is less than $\mathrm{s}$, the slope should go downward from the first adjustment to the second. Thus, the attitude adjustment in the W-S sequence is different from that in the S-W sequence. Therefore, an order effect is predicted with the use of numerical information in evaluation.

Two experiments were conducted to test these hypotheses. Experiment 1 tested the case of positive adjustment, and Experiment 2, the negative adjustment. Before the main experiments, a pilot study was conducted to establish the correspondences between verbal and numerical formats.

\section{PILOT STUDY}

The purpose of the pilot study was to establish correspondences between verbal and numerical formats. Wallsten and Barton (1982) conducted a series of studies to establish the probability distributions for various probability terms. The distributions can be used to infer the numeral correspondences of these probability terms. In a similar manner, the present pilot study collected the numerical correspondences for several verbal terms that are commonly used in product evaluations.

The data were collected in two stages. First, 20 commonly used verbal evaluative adjectives were selected from a Chinese dictionary. Two independent judges, blind to the purpose of the study, inspected these terms and selected the most suitable ones to use for product quality descriptions based on the criteria of familiarity and frequency of usage. Four adjectives were selected as a result. They were "very good," "good," "bad," and "very bad." In the second stage, 30 undergraduate students from Yuan-Ze University in Taiwan were asked to assign a percentile to each adjective to represent the corresponding numerical value of the terms. In the study, the terms were inserted in sentences which read "I think this product is XXX," where XXX were the four adjectives. The participants were asked to mark down how good the product should be in its class in order to be evaluated as XXX on a 100-point scale. The sentences were printed on a piece of paper, and beneath each sentence there were 11 number anchors $(0 \%, 10 \%, 20 \% \ldots 100 \%)$ While reading a sentence such as "I think this product is very good," a participant was asked to check a number to represent how good the product in its class is in order to be evaluated as "very good." For instance, if the participant thought the product must be better than $90 \%$ of its competitors in order to be a "very good" product, then she/he should check the $90 \%$ mark. Thus the number the participant checked represented the corresponding percentile of the product on the numerical scale for the respective verbal label.

We used the mode of responses for a term to represent the numeral value corresponding to the verbal label of the term. The results were as the follows: "very good" corresponds to $90 \%(S D=$ $5.19 \%$; range $=80-100 \%)$, "good" to $70 \%(S D=$ $7.23 \%$; range $=50-90 \%)$, "bad" to $30 \%(S D=$ $8.79 \%$; range $=10-40 \%$ ), and "very bad" to $10 \%$ $(S D=6.85 \%$; range $=0-30 \%)$.

\section{EXPERIMENT 1}

Experiment 1 tested the hypothesis that verbal and numerical information formats induce different belief updating operations. In the experiment, the participants were asked to evaluate a product based on two pieces of information, which might be in either verbal or numerical format and which were presented in a sequence. They were asked to express their purchase likelihood of the product after they received each piece of information. As described above, the verbal format was assumed to afford an additive integration operation and thus no order effect was expected for those who received verbal information. In contrast, the numerical format was expected to activate an averaging operation and as a result an order effect was expected for those who received numerical information. Experiment 1 tested the case of the positive purchase likelihood updating processes in which experts' product evaluations were in positive directions, while Experiment 2 tested the case of negative adjustments in which experts' product evaluations were in negative directions.

\section{Method}

\section{Participants}

The participants of this experiment were 80 undergraduate students from Yuan-Ze University 
in Taiwan. They participated in the experiment either to fulfil a course requirement or to earn extra course credits.

\section{Materials and procedure}

Two independent variables (information format, presentation order) were manipulated between subjects. The factorial combinations of the two variables yielded four experimental conditions. Thus there were 20 participants in each condition, and each participant was given one of the four conditions only. These four conditions were, in the verbal format, strong-weak vs. weak-strong sequence, and in the numerical format, strongweak vs. weak-strong sequence. In the verbal condition, the evaluations were presented in sentences similar to the following: "The stereo system is $\mathrm{xxx}$ compared with the other products of its kind." The "xxx" was one of the two positive verbal evaluations, that is, good (weak evaluation) and very good (strong evaluation). In the numerical condition, the evaluation was described as "The stereo system is better than $\mathrm{xxx}$ of the other products in its class." Here, the "xxx" was the numerical counterparts of the two positive verbal evaluations, i.e., $70 \%$ (weak evaluation) and $90 \%$ (strong evaluation). Orders referred to the presentation order of the two evaluations. In the weak-strong sequence, the weak evaluation appeared before the strong one, and in the strong-weak sequence, the strong evaluation was presented before the weak one.

A booklet was designed containing the experimental materials. In the booklet, the participants read a scenario that described a person intending to buy a stereo and explained that there was a new compact stereo system just being launched to the market. The person wanted to find more information concerning the new stereo system in order to make a purchase decision. He surfed the web and found two expert evaluations of the product from Consumer Reports.

The booklet went on to describe the experts' evaluations, which were presented on two separate pages. The participants were asked to assume the person's role to express their purchase likelihood based on the experts' evaluations. Following the measure frequently used in studying the belief updating model (Hogarth \& Einhorn, 1992), the present experiment measured participants' purchase likelihood on a probability scale. To create an initial anchor point for the anchoring-andadjustment, the participants were first told that because this is a new product of which consumers do not have much knowledge, they should hold a neutral attitude toward the product. As a consequence, the participants were asked to set their purchase likelihood at the middle point (i.e., 50\%) of the scale. This initial anchor set a baseline of judgments for later adjustments.

The experts' evaluations for the compact stereo system were in either the verbal or numerical format. After reading the first evaluation, the participants were asked to make their first judgment of purchase likelihood. For instance, in the verbal format and the strong-weak sequence, participants first received a strong verbal product evaluation from an expert (i.e. "very good"), and they evaluated the product based on this strong verbal evaluation alone. After they made their first rating, they went on to read the second evaluation. At this point, they were asked to rate the purchase likelihood based on both evaluations. In the above example, the participants received the second, weak verbal evaluation (i.e. "good") from another expert, and they evaluated the product based on both evaluations. When the participants finished both evaluations, they were debriefed, given their due course credits, and thanked for their participation.

\section{Results and discussion}

The result of the verbal condition is presented in Figure 1, which shows the means of the two presentation-order conditions after each adjustment. The comparable result of the numerical format condition is presented in Figure 2.

The results were analysed by an analysis of variance (ANOVA) with two between-subject factors (information format, order). The analysis revealed a nonsignificant main effect of

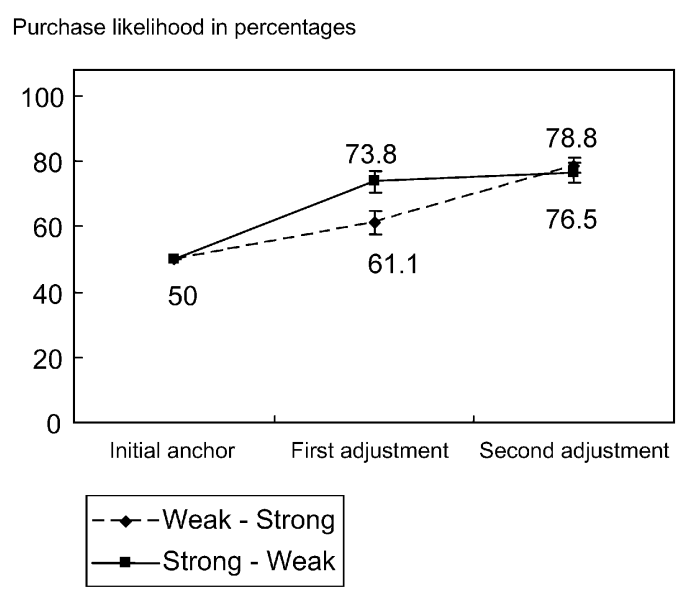

Figure 1. Positive purchase likelihood adjustments in the verbal format conditions (vertical bars represent standard errors). 
Purchase likelihood in percentages

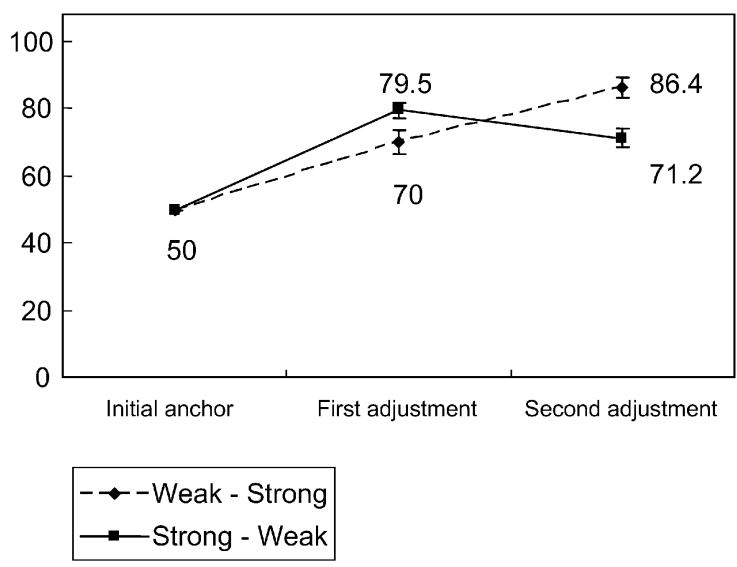

Figure 2. Positive purchase likelihood adjustments in the numerical format conditions (vertical bars represent standard errors).

Information Format, $F(1,76)=0.171, M S e=$ $161.59, n s$, and a significant main effect of Presentation Order on final judgments, $F(1,76)$ $=9.42, \mathrm{MSe}=161.59, p<.01$. Most importantly, the interaction effect of Information Format $x$ Order was significant, $F(1,76)=5.19, M S e=$ 161.59, $p<.05$. As can be seen from Figures 1 and 2, both the weak-strong and strong-weak sequences led to upward adjustments and similar final judgments in the verbal format condition (from $61.1 \%$ to $78.8 \%$ for the weak-strong sequence; from $73.8 \%$ to $76.5 \%$ for the strongweak sequence). This supports the hypothesis that the additive rule is in effect in the verbal format condition (i.e. $\mathrm{w}+\mathrm{s}=\mathrm{s}+\mathrm{w}$.) Regardless of the presentation order, the final judgments are the same. In contrast, the averaging rule is evident in the numerical format condition. For the strongweak sequence, the second piece of weak information drags the final judgments downward (from $79.5 \%$ to $71.2 \%$ ) because $(\mathrm{s}+\mathrm{w}) / 2<\mathrm{s}$. For the weak-strong condition, belief is adjusted upward (from $70 \%$ to $86.4 \%$ ) because $(\mathrm{w}+\mathrm{s}$ ) $/ 2>\mathrm{w}$. This supports the hypothesis that the averaging rule is at work in the numerical format condition.

To test the research hypotheses, the adjustments of different orders were compared, conditional on the information format conditions. The rating data of the verbal condition were further analysed using a mixed model of ANOVA with one between-subject factor (Information Presentation Order: weak-strong vs. strong-weak) and one within-subject factor (Evaluation Sequence: first rating vs. second rating). The results showed a nonsignificant main effect of Information Presentation Order, $F(1,38)=1.77, M S e=$ 305.16, $n s$, but a significant main effect of
Evaluation Sequence, $F(1,38)=18.98, M S e=$ 109.64, $p<.01$. Most importantly, there was a significant interaction effect between the Information Presentation Order and the Evaluation Sequence, $F(1,38)=10.13, M S e=109.64, p<$ .01 . With the verbal format, the first adjustment in the strong-weak sequence group $(M=73.8 \%, S D=$ $15.5 \%)$ was significantly higher than that in the weak-strong sequence group $(M=61.1 \%, S D=$ $16.6 \%) ; t(38)=2.5, p<.05$. In contrast, the second judgment in the weak-strong sequence $(M=78.8 \%$, $S D=10.7 \%$ ) was not different from that in the strong-weak sequence $(M=76.5 \%, S D=14.2 \%)$; $t(38)=0.57, n s$. The pattern of the results was congruent with our prediction, and indicates that the participants used an additive rule to integrate the information in the verbal format condition.

The data pattern in the numerical format condition was different. The similar mixed model of ANOVA with one between-subject factor (Information Presentation Order: weak-strong vs. strong-weak) and one within-subject variable (Evaluation Sequence: first rating vs. second rating) was applied to the data. The results showed a nonsignificant main effect of Information Presentation Order, $F(1,38)=0.61, M S e=$ $270.07, n s$, and a marginally significant main effect of Evaluation Sequence, $F(1,38)=4.05, M S e=$ 81.96, $p=.05$. Again, there was a significant interaction effect between the Information Presentation Order and the Evaluation Sequence, $F(1,38)=37.07, M S e=81.96, p<.01$. The first adjustment of the strong-weak group $(M=79.5 \%$, $S D=11.0 \%$ ) was significantly higher than that of the weak-strong group $(M=70.0 \%, S D=$ $15.9 \%) ; t(38)=2.19, p<.05$. However, this data pattern was reversed in the second adjustment, where the adjustment of the strong-weak group ( $M=71.2 \%, S D=12.0 \%)$ was significantly lower than that in the weak-strong group $(M=86.4 \%$, $S D=13.7 \%) ; t(38)=-3.74, p<.01$. This finding contrasted with the results of the verbal condition, in which the participants' final ratings were the same for the W-S and the S-W sequences. The different results indicate that the participants of the two information format conditions used different strategies to integrate the experts' evaluations, and the pattern of the results obtained in the numerical condition provides evidence supporting the operation of the averaging rule here.

\section{EXPERIMENT 2}

Experiment 1 explored how people integrated positive information to adjust their purchase 
likelihood. In this experiment, the same hypothesis-that different types of information afford different types of integration operations - was tested using negative information as test materials. The predictions of Experiment 2 were similar to the predictions of Experiment 1, except that the direction of the purchase likelihood adjustment is negative. Just as in Experiment 1, for the first rating, participants receiving strong negative information (i.e., the $\mathrm{S}-\mathrm{W}$ condition) were expected to adjust their purchase likelihood of the product downward more than those receiving weak negative information (i.e., the W-S condition), irrespective of the format of the information. However, for the second rating, because the information format is expected to affect the way that information is integrated, it was predicted that no order effect would occur in the verbal condition, where an additive rule is assumed to be in effect. Meanwhile, in the numerical condition, where the averaging rule underlies the cognitive process, an order effect was expected.

\section{Method}

\section{Participants}

The participants were 121 undergraduate students selected from the same subject pool as in Experiment 1. Except for the verbal $\times$ weakstrong sequence condition, which contained 31 participants, there were 30 participants in each condition.

\section{Materials and procedure}

The design of materials and the procedure of data collections of Experiment 2 were identical to those of Experiment 1. The only difference was that the negative evaluation information was manipulated in Experiment 2. In the verbal condition, "bad" and "very bad" were used, with their numerical counterparts set at $30 \%$ and $10 \%$, respectively.

\section{Results and discussion}

Figure 3 and 4 present the plots indicating the mean values of judgments in the experimental conditions. As in Experiment 1, an order effect occurs with the numerical format but not with the verbal format. The results of an ANOVA with two between-subject factors (Information Format, Order) revealed significant main effects for both Information Format, $F(1,117)=26.32, M S e=$

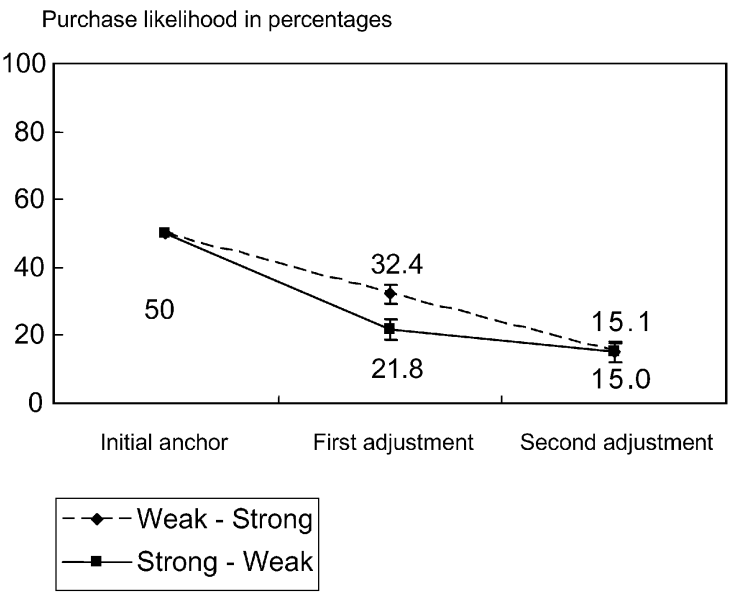

Figure 3. Negative purchase likelihood adjustments in the verbal format conditions (vertical bars represent standard errors).

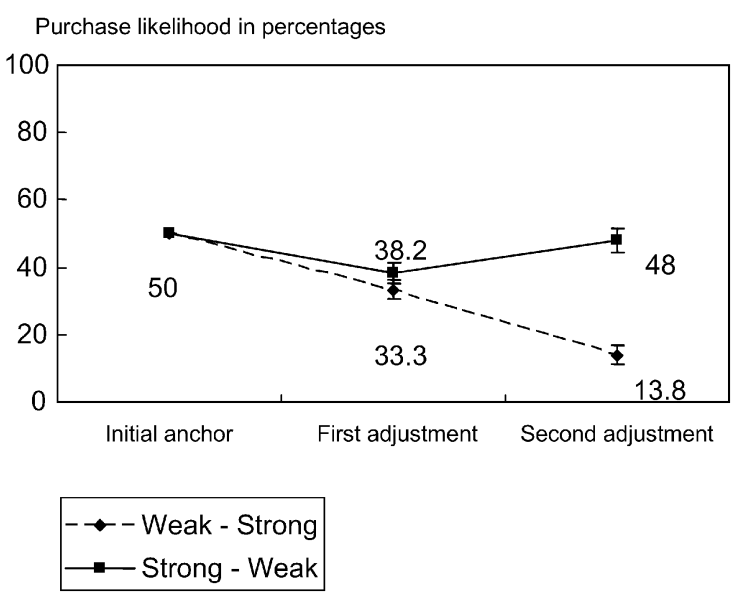

Figure 4. Negative purchase likelihood adjustments in the numerical format conditions (vertical bars represent standard errors).

$290.54, p<.01$, and Order $F(1,117)=30.21, M S e$ $=290.54, p<.01$. Again, the most interesting result is the significant interaction effect between the two factors, $F(1,117)=30.55, M S e=290.54$, $p<.01$. With the verbal format, both W-S and S$\mathrm{W}$ sequences led to downward adjustments and similar final adjustments (from $32.4 \%$ to $15.1 \%$ for the W-S sequence; from $21.8 \%$ to $15.0 \%$ for the S$\mathrm{W}$ sequence.) This is the supportive evidence for the additive operation in the verbal format condition. With the numerical format, the W-S sequence leads to a straight downward adjustment (from $33.3 \%$ to $13.8 \%$ ), but the S-W sequence leads to a rebound of judgments where the second adjustment is higher than the first (from $38.2 \%$ to $48.0 \%$ ). This is evidence that the averaging rule is in effect in the numerical format condition. 
Further analyses were also performed to test the experimental hypotheses. As in Experiment 1, the data of the verbal condition were further analysed using a mixed model of ANOVA with one between-subject factor (Information Presentation Order: W-S vs. S-W) and one within-subject factor (Evaluation Sequence: first rating vs. second rating). The results showed a nonsignificant main effect of Information Presentation Order, $F(1,59)$ $=1.95, \mathrm{MSe}=445.6, \mathrm{~ns}$, but a significant main effect of Evaluation Sequence, $F(1,59)=59.88$, $M S e=74.68, p<.01$. The most important result was the significant interaction effect of Information Presentation Order $\times$ Evaluation Sequence, $F(1$, $59)=11.23, M S e=74.68, p<.01$. In the verbal format condition, the downward adjustment in the negative direction of the $\mathrm{S}-\mathrm{W}$ group $(M=$ $21.8 \%, S D=16.8 \%$ ) was significantly stronger than that of the W-S group in the first adjustment $(M=32.4 \%, S D=14.7 \%) ; t(59)=-2.62$, $p=.01$. Nonetheless, the difference in the second adjustment between the $\mathrm{S}-\mathrm{W}$ group $(M=15.0 \%$, $S D=17.2 \%)$ and the W-S group $(M=15.1 \%$, $S D=15.8 \%)$ is not significant, $t(59)=-0.023$, $n s)$. This data pattern supports the hypothesis that the additive rule is in effect when information is presented in a verbal format.

The adjustments in the numerical format condition were different. The similar mixed model of ANOVA with one between-subject factor (Information Presentation Order: W-S vs. S-W) and one within-subject factor (Evaluation Sequence: first rating vs. second rating) was applied to the data. The results showed a significant main effect of the Information Presentation Order, $F(1,58)=23.25, M S e=$ $490.68, p<.01$, as well as a significant main effect of the Evaluation Sequence $F(1,58)=6.84, M S e$ $=102.51, p<.05$. Once again, there was a significant Information Presentation Order $\times$ Evaluation Sequence interaction effect $F(1,58)=$ $62.95, M S e=102.51, p<.01$. The sample mean of the first adjustment in the S-W group $(M=38.2 \%$, $S D=17.6 \%)$ was weaker than that in the W-S group $(M=33.3 \%, S D=16.1 \%)$ in the negative direction, but the difference was not statistically significant, $t(58)=1.11, n s$. In contrast, the second adjustment in the W-S sequence $(M=13.8 \%, S D$ $=15.2 \%)$ was significantly lower than that in the S-W sequence $(M=48.0 \%, S D=19.7 \%) ; t(58)=$ $-7.52, p<.001$. The contrast between the straight downward adjustments in the W-S sequence and the rebound of adjustments in the S-W sequence supports the hypothesis that the averaging rule underlies information integration presented in a numerical format.
Taken together, as in Experiment 1, these results once again support the key hypotheses of the present research, that the verbal format induces an additive integration rule while the numerical format induces an averaging rule. These results, along with those from Experiment 1, support the general idea that different information presentation formats can induce different information integration rules.

An unexpected result was observed in the numerical format condition of Experiment 2. Although not statistically significant, weak negative information led to a more negative mean evaluation than strong negative information in the first adjustment. It is not clear why this unexpected finding has occurred, but some possibilities are presented. First, the present experiments called for an anchoring-and-adjustment process (Tversky \& Kahneman, 1974), with an initial anchor set at $50 \%$. Insufficient adjustments were commonly found in such a process. It is possible that the experimental participants may have made insufficient adjustments given the first piece of strong negative information, resulting in the observed data patterns. The similar insufficient adjustments can be found in other experimental conditions, in which the mean adjustments are more moderate than their corresponding experimental stimuli. Second, this study used a less efficient betweensubject design, in which larger random errors between subjects exist. Nonetheless, these suggestions are only speculative in nature. It requires carefully designed experiments to explore the validity of these explanations.

\section{GENERAL DISCUSSION}

The results of the present research provide support for the idea that stimulus items with different linguistic formats corresponding to the same quantitative meanings lead to different judgments. Based on the differences in the affordability between the verbal and numerical information, the belief updating model predicts that the use of numerical stimuli will trigger an averaging rule to integrate information; as a result, order effects are predicted. In contrast, the use of verbal information will trigger an additive rule that would not lead to the order effect. These predictions received support in both Experiment 1 for positive adjustments and Experiment 2 for negative adjustments.

One major contribution of the current study is to point out that a difference in the cognitive processes underlying the way people update their beliefs depends on the use of different linguistic 
formats in product evaluations. Past research tended to presume the use of certain specific rules for information integration (e.g., Johar et al., 1997; West \& Broniarczyk, 1998). The present study, in contrast, emphasizes the contingency nature of rule selections (Payne et al., 1993.) Our results seem to suggest that people have a repertoire of information integration rules at hand. The application of a specific rule can be influenced by task demands. In particular, this study shows that there is an affordance relationship between the format of information and the rules used to integrate the information. The experiments point out specifically which rule will be used to integrate verbal information and which rule will be used to integrate numerical information. Our results indicate that one should be cautious in applying different formats of information when designing experiments. Results from these experiments could be explained in part by the formats of information and the orders of information presentations. Our results also indicate that the order of the information presented in an advertisement should be carefully designed in accordance with the information format.

\section{Limitations and future directions}

One limitation of this study has to do with the direction of belief adjustments. The present study focused on a special case of belief updating in which both pieces of information are in the same direction. Hogarth's belief updating model can potentially accommodate situations where information valences are different. Past studies have used mixed information in their designs to test a primacy vs recency effect (Anderson, 1981), or the impact of information in different serial positions (Jacoby et al., 2002). In these studies the processing rules are assumed by default. The current study, in contrast, explored conditions in which different rules are adopted. Future studies should extend this line and investigate cases in which both positive and negative information is present.

Future research can also address other factors that determine the use of a specific integration rule. Besides linguistic formats, there could be other task or context factors, such as time constraints or the amount of information, that could influence which rule is selected (Payne et al., 1993.) There is evidence indicating that people tend to use simplified choice strategies with excess amounts of information or under time pressure in the multiattribute choice situation (e.g., Payne, 1982). It is also possible that the information integration rules would vary as a function of these task and context factors. In addition, the probability judgment literature (e.g., Wallsten, Budescu, Erev, \& Diederich, 1997) concerning the interactions of the information structure, individual's cognitive models, and information combination rules could also provide further insights for the present research.

Finally, there also may be individual differences in selecting information integration rules. For example, accountants and auditors often use probability terms to communicate their risk assessments of a company (Johnson 1995; Wang 1998). It is their routine work to integrate risk information from various sources, and the stake of their decision is high. These trained people may have less difficulty in applying more complicated integration rules, and hence may act differently from nontrained people. Moreover, people given monetary incentives to improve their judgmental accuracy may employ different, potentially more complicated, integration rules from those who are not motivated by such incentives. Future research should identify these factors and investigate how they affect the belief updating processes.

Manuscript received April 2006

Revised manuscript accepted October 2006

\section{REFERENCES}

Anderson, N. (1981). Foundations of information integration theory. New York: Academic Press.

Anderson, N. (1991). A cognitive theory of judgment and decision. In N. Anderson (Ed.), Contributions to information integration theory: Vol. 1, Cognition (pp. 105-142). Hillsdale, NJ: Lawrence Erlbaum Associates Inc.

Benassi, M. (1982). Effects of order presentation, primacy, and physical attractiveness on attributions of ability. Journal of Personality and Social Psychology, 43, 48-58.

Carlson, R. A., \& Dulany, D. E. (1988). Diagnostic reasoning with circumstantial evidence. Cognitive Psychology, 20, 463-492.

Childers, T. L., \& Viswanathan, M. (2000). Representation of numerical and verbal product information in consumer memory. Journal of Business Research, 47, 109-120.

Curley, S. P., Young, M. J., Kingry, M. J., \& Yates, J. F. (1988). Primacy effects in clinical judgments of contingency. Medical Decision Making, 8, 216222.

Einhorn, H., \& Hogarth, R. (1986). Ambiguity and uncertainty in probabilistic inference. Psychological Review, 92, 433-461.

Furnham, A. (1986). The robustness of the recency effect: Studies using legal evidence. The Journal of General Psychology, 113, 351-357.

Gibson, J. J. (1977). The theory of affordances. In R. Shaw \& J. Bransford (Eds.), Perceiving, acting and knowledge: toward an ecological psychology 
(pp.67-82). New York: Lawrence Erlbaum Associates Inc.

Graesser, C. C., \& Anderson, N. (1974). Cognitive algebra of the equation: gift size $=$ generosity $\times$ income. Journal of Experimental Psychology, 103, 692-699.

Hogarth, R. M., \& Einhorn, H. J. (1992). Order effects in belief updating: The belief-adjustment model. Cognitive Psychology, 24, 1-55.

Huber, J., Payne, W. J., \& Puto, C. (1982). Adding asymmetrically dominated alternatives: Violations of regularity and similarity hypothesis. Journal of Consumer Research, 9, 90-98.

Hue, C., Peng, C., Shen, Y., \& Yang, J. (1990). A numerical translation of Chinese probability terms. Chinese Journal of Psychology, 31, 1-6.

Jacoby, J., Morrin, M., Jaccard, J., Gurhan, Z., Kuss, A., \& Maheswaran, D. (2002). Mapping attitude formation as a function of information input: Online processing models of attitude formation. Journal of Consumer Psychology, 12, 21-34.

Johar, G. V., Jedidi, K., \& Jacoby, J. (1997). A varyingparameter averaging model of on-line brand evaluation. Journal of Consumer Research, 24, 232-247.

Johnson, E. N. (1995). Effects of information order, group assistance and experience on auditors' sequential belief revision. Journal of Economic Psychology, 16, 137-160.

Levin, I. P., Johnson, R. D., \& Faraone, S. V. (1984). Information integration in price-quality tradeoffs: The effect of missing information. Memory and Cognition, 12, 96-102.

Lichtenstein, M., \& Srull, T. (1987). Processing objectives as a determinant of the relationship between judgment and recall. Journal of Experimental Social Psychology, 23, 93-118.

Lindberg, E. T., Garling, T., \& Montgomery, H. (1988). People's beliefs and values as determinants of housing preferences and simulated choices. Scandinavian Housing and Planning Research, 5, 181-197.

Lindberg, E. T., Garling, T., \& Montgomery, H. (1991). Prediction of preferences for choice between verbally and numerically described alternatives. Acta Psychologica, 76, 165-176.

Lopes, L. L. (1982). Toward a procedural theory of judgment. Technical report, Wisconsin Human Information Processing Program (WHIPP 17), Madison, WI.

Lopes, L. L. (1985). Averaging rules and adjustment processes in Bayesian inference. Bulletin of the Psychonomic Society, 23, 509-512.

Lopes, L. L. (1987). Procedural debiasing. Acta Psychologica, 64, 167-185.

Luchins, A. S., \& Luchins, E. H. (1986). Primacy and recency effects with descriptions of moral and immoral behavior. The Journal of General Psychology, 113, 159-177.

Nisbett, R., \& Ross, L. (1980). Human inference: Strategies and shortcomings of human judgment. Englewood Cliffs, NJ: Prentice-Hall.
Payne, J. W. (1982). Contingent decision behavior. Psychological Bulletin, 92, 382-402.

Payne, J. W., Bettman, J. R., \& Johnson, E. J. (1993). The adaptive decision maker. New York: Cambridge University Press.

Pennington, N., \& Hastie, R. (1986). Evidence evaluation in complex decision making. Journal of Personality and Social Psychology, 51, 242-258.

Scammon, D. L. (1977). Information load and consumers. Journal of Consumer Research, 4, 148-155.

Sen, S. (1998). Knowledge, information mode, and the attraction effect. Journal of Consumer Research, 25, 64-77.

Shanteau, J. (1975). Averaging versus multiplying combination rules of inference judgment. Acta Psychologica, 39, 83-89.

Stone, D. N., \& Schkade, D. A. (1991). Numeric and linguistic information representation in multiattribute choice. Organizational Behavior and Human Decision Processes, 49, 42-59.

Stone, D. N., \& Schkade, D. A. (1994). Effects of attribute scales on process and performance in multiattribute choice. Organizational Behavior and Human Decision Processes, 59, 261-287.

Tetlock, P. E. (1983). Accountability and the perseverance of first impressions. Social Psychology Quarterly, 46, 285-292.

Tversky, A., \& Kahneman, D. (1974). Judgment under uncertainty: heuristics and biases. Science, 185, 1124-1131.

Viswanathan, M., \& Childers, T. L. (1996). Processing of numerical and verbal product information. Journal of Consumer Psychology, 5, 359-385.

Viswanathan, M., \& Narayanan, S. (1992). The processing of numerical versus verbal attribute information: A study using information patterns. Marketing Letters, 3, 201-208.

Viswanathan, M., \& Narayanan, S. (1994). Comparative judgments of numerical and verbal attribute levels. Journal of Consumer Psychology, 3, 79-101.

Wallsten, T. S., \& Barton, C. (1982). Processing probabilistic multidimensional information for decisions. Journal of Experimental Psychology: Learning, Memory, and Cognition, 8, 361-384.

Wallsten, T. S., Budescu, D. V., Erev, I., \& Diederich, A. (1997). Evaluating and combining subjective probability estimates. Journal of Behavioral Decision Making, 10, 243-268.

Wang, H. (1998). The impact of communication with probability phrases in auditing decisions. Unpublished doctoral dissertation, National Taiwan University.

West, P. M., \& Broniarczyk, S. M. (1998). Integrating multiple opinions: The role of aspiration level on consumer response to critic consensus. Journal of Consumer Research, 25, 38-51.

Yalch, R. F., \& Yalch, R. (1984). The effect of numbers on the route of persuasion. Journal of Consumer Research, 11, 522-527.

Yates, J. F., \& Curley, S. P. (1986). Contingency judgment: Primacy effects and attention decrement. Acta Psychologica, 62, 293-302. 
Copyright of International Journal of Psychology is the property of Routledge and its content may not be copied or emailed to multiple sites or posted to a listserv without the copyright holder's express written permission. However, users may print, download, or email articles for individual use. 